\title{
BMJ Open End-of-life cost and its determinants for cancer patients in urban China: a population-based retrospective study
}

\author{
Zhong Li, ${ }^{1}$ Zijing Pan, ${ }^{1}$ Liang Zhang, ${ }^{1}$ Ruibo He, ${ }^{1}$ Shan Jiang, ${ }^{2}$ Chengzhong Xu, ${ }^{3}$ \\ Fangfang Lu, ${ }^{3}$ Pei Zhang, ${ }^{3}$ Boyang $\mathrm{Li}^{1}$
}

To cite: Li Z, Pan Z, Zhang L, et al. End-of-life cost and its determinants for cancer patients in urban China: a population-based retrospective study. BMJ Open 2019;9:e026309. doi:10.1136/ bmjopen-2018-026309

- Prepublication history for this paper is available online. To view these files, please visit the journal online (http://dx.doi org/10.1136/bmjopen-2018026309).

ZL and ZP contributed equally.

Received 29 August 2018 Revised 22 January 2019 Accepted 30 January 2019

D) Check for updates

C Author(s) (or their employer(s)) 2019. Re-use permitted under CC BY-NC. No commercial re-use. See rights and permissions. Published by BMJ.

${ }^{1}$ School of Medicine and Health Management, Tongji Medical College, Huazhong University of Science and Technology, Wuhan, China

${ }^{2}$ School of Health Policy and Management, Nanjing Medical University, Nanjing, China

${ }^{3}$ Yichang Center for Disease Control and Prevention, Yichang, China

Correspondence to

Dr Boyang Li;

jimmylee1900@foxmail.com

\section{ABSTRACT}

Objective This study aimed to define the end-of-life (EOL) healthcare utilisation and its cost and determinants for cancer patients and to proactively inform related strategies in mainland China.

Design A population-based retrospective study.

Setting and participants Data from 894 cancer patients were collected in urban Yichang, China from 01 July 2015 to 30 June 2017.

Outcome measures Emergency department (ED) visits, outpatient and inpatient hospitalisation services, intensive care unit (ICU) admission and total costs were used as the main outcomes.

Results In this study, $66.8 \%$ of the 894 patients were male, and the average age was 60.4 years. Among these patients, $37.6 \%$ died at home, and patients had an average of 4.86 outpatient services, 2.23 inpatient hospitalisation services and 1.44 ED visits. Additionally, $5.9 \%$ of these patients visited the ICU at least once. During the EOL periods, the costs in the last 6 months, 3 months, 1 month and 1 week were US\$18 234, US\$13 043 , US\$6349 and US\$2085, respectively. The cost increased dramatically as death approached. The estimation results of generalised linear regression models showed that aggressive care substantially affected expenditure. Patients with Urban Employee Basic Medical Insurance spent more than those with Urban Resident-based Basic Medical Insurance or the New Rural Cooperative Medical Scheme. The place of death and the survival time are also risk factors for increased EOL cost.

Conclusion The findings suggested that the EOL cost for cancer patients is associated with aggressive care, insurance type and survival time. Timing palliative care is urgently needed to address ineffective and irrational healthcare utilisation and to reduce costs.

Ethics and dissemination This study was approved by the Ethics Committee of the Tongji Medical College, Huazhong University of Science and Technology (IORG No.: IORG0003571). All the data used in this study were deidentified.

\section{INTRODUCTION}

Cancer is the leading cause of mortality and accounted for 14.1 million new cancer cases, 32.6million individuals living with cancer, and 8.2 million deaths worldwide in 2012. ${ }^{1}$ Cancer greatly affects low-income and

\section{Strengths and limitations}

This population-based study was the first to systematically estimate the end-of-life (EOL) health expenditure for cancer patients in mainland China. It is important to estimate the palliative care demand and guide its system building.

- This study introduced EOL healthcare utilisation and cost in China and quantified the relationship between them.

- This study will guide health policy regarding the delivery of high-quality, cost-effective cancer care systems.

- Given the anonymity of the data, we cannot obtain the health records from primary care facilities and healthcare utilisation outside Yichang. Thus, the EOL healthcare cost might have been underestimated.

- The unique socioeconomic status of the selected population may reduce the generalisability of our findings. Further studies on the provincial or national levels are essential to provide systematic evidence.

middle-income countries and is expected to account for $70 \%$ of the newly reported cancer cases worldwide by $2030{ }^{2}$ Given the considerable share of the total health expenditure on cancer (approximately, 6.0\% in European countries $^{3}$ and $9.2 \%$ in Taiwan ${ }^{4}$ ) and the great gap in the cancer healthcare delivery system between developed and developing countries, ${ }^{2}$ evaluating the end-of-life (EOL) cost and identifying its key determinants have been a worldwide concern. ${ }^{6}$

Several systematic reviews have noted that in-home EOL care can improve patient satisfaction, as well as reducing inpatient hospitalisation utilisation and hospital death. ${ }^{78}$ These reviews also indicated that aggressive procedures do not improve the quality of life. ${ }^{910}$ However, health expenditure and utilisation show large geographic variations among patients in the USA with high medical care intensity during the EOL period, thereby producing poor outcomes and confusing the patients' preference. ${ }^{1-13}$ 
EOL hospitalisation relatively lacks value worldwide with its unsustainable expenditure, ${ }^{14} 15$ whereas palliative care is relatively underutilised, though it is proven to save costs. ${ }^{16}$ These phenomena thereby aggravated inequality among patients with different socioeconomic statuses and decrease overall efficacy. ${ }^{17-19}$

According to the Fifth Chinese National Health Services Survey in 2013, the incidences of malignant neoplasms in China reached $0.35 \%$ and $0.23 \%$ in the urban and rural areas, respectively, higher than those in 2008. ${ }^{20}$ The most common cancer types in China are lung and stomach cancers, accounting for $22 \%$ of new global cancer cases and deaths, and liver and oesophageal cancers, accounting for $27 \%$ of new global cancer cases and deaths. ${ }^{21}$ Although the age-standardised 5-year relative survival rate has increased from $30.9 \%$ (2003$2005)$ to $40.5 \%$ (2012-2015), geographical differences in cancer survival still remain. ${ }^{22}$ The Program of Cancer Prevention and Control in China (2004-2010) reported that the decreased mortality rates and the substantial geographic variation in the survival rates have become a burden to the health system, especially with the high out-of-pocket (OOP) expenditure. ${ }^{2123}$ The Economist Intelligence Unit noted that China ranked 71 among 80 countries in a survey on the quality of death. ${ }^{24} \mathrm{~A}$ cross-sectional study in China found that OOP expenditures for cancer patients accounted for $57.5 \%$ of the annual household income. ${ }^{25}$ This percentage is higher than that $(23.7 \%)$ in the USA. ${ }^{26}$ Given the limitations of medical insurance coverage and reimbursement rate, cancer patients and their families face extremely high health expenditures. ${ }^{27} 28$ Hospital type, education, insurance type and household income can also predict the expenditure of cancer care. ${ }^{25}$ Research on the EOL healthcare cost in mainland China has received considerable interest in terms of policy. Studies have noted that some treatments for cancer patients in tertiary hospitals are unnecessary, especially during the patients' last days. ${ }^{21} 2930$ However, cross-sectional studies mainly focus on the total healthcare cost limited to the single-institutional level; thus, underestimating the actual expenditure. ${ }^{31}$ A population-based study examining EOL healthcare expenditure and its determinants is not explored, especially in terms of the real-world data of the regional health system in China. Therefore, in this study, we aimed (1) to define the EOL healthcare utilisation and its cost among cancer patients, (2) to investigate the determinants of EOL healthcare cost and (3) to inform related policy making and implementation in China.

\section{METHODS}

\section{Data collection}

On the basis of the International Statistical Classification of Diseases and Related Health Problems, 10th Revision (ICD-10), and the WHO version for 2016, ${ }^{32}$ the present study selected patients diagnosed with
C00-C97 in urban Yichang, China. Residents who died from cancer from 01 July 2015 to 30 June 2017 were continuously enrolled in this study. The demographic information of cancer patients, data on the place of death and cancer type were collected from the National Population Death Registration and Management System established in 2013. All healthcare utilisation and cost data were provided by the Yichang Health Management Center affiliated with the Yichang Center for Disease Control and Prevention integrating hospital information system, health insurance database and population information database with the identification card number.

\section{Variables}

Patients were divided into three groups: younger than 65 years, $65-80$ years old and 80 years or older when diagnosed. ${ }^{21}$ Survival was divided into four types, ${ }^{33}$ namely, education, marital status, cancer type and medical insurance type. The place of death was routinely coded as a binary variable. The recommended benchmark measures for terminal cancer care were used to identify the aggressive and palliative procedures. ${ }^{34-38}$ The main outcome was healthcare utilisation, including outpatient and inpatient hospitalisation services, emergency department (ED) visits and intensive care unit (ICU) admission, and the EOL expenditures. To compare the results, we converted the cost data to the international purchasing power parities using the rate for Chinese Yuan to US\$ (¥2.03=US\$1) in health from the International Comparison Program $2011^{39}$

\section{Patient and public involvement}

All the data were provided by the Yichang Health Management Center affiliated with the Yichang Center for Disease Control and Prevention and de-identified before statistical analysis. Therefore, identifiable cancer patients were not involved in the recruitment or implementation of this study.

\section{Statistical analysis}

Descriptive analysis was used to describe the detailed information about the enrolled population. Generalised linear models were used to evaluate the mechanism of the effect of independent variables on the EOL cost because the EOL data were severely positively skewed. ${ }^{40}{ }^{41}$ Four regression models were conducted for patients with different lengths of survival, the EOL costs were the outcome variables, and the independent variables were as follows: $(1)$ age $(<65,65-80$ and $\geq 80$ years), (2) gender (male/female), (3) education level, (4) marital status, (5) first cancer type, (6) medical insurance type, (7) number of outpatient services, (8) number of ED visits, (9) number of inpatient hospitalisation services, (10) number of ICU admissions and (11) survival. All the above-mentioned data were calculated with Stata V.14.0. Differences at $p<0.05$ were considered statistically significant. 


\begin{tabular}{|c|c|c|}
\hline Demographic characteristics & $\begin{array}{l}\text { Patients } \\
(\mathrm{n}=894)\end{array}$ & $\%$ \\
\hline Age (year), median (range) & $\begin{array}{l}69 \\
(25 \text { to } 102)\end{array}$ & \\
\hline$<65$ & 315 & 35.2 \\
\hline $65-80$ & 440 & 49.2 \\
\hline$>80$ & 139 & 15.6 \\
\hline \multicolumn{3}{|l|}{ Gender } \\
\hline Male & 597 & 66.8 \\
\hline Female & 297 & 33.2 \\
\hline \multicolumn{3}{|l|}{ Marital status } \\
\hline Unmarried & 9 & 1.0 \\
\hline Married & 742 & 83.0 \\
\hline Widow & 126 & 14.2 \\
\hline Divorced & 17 & 1.9 \\
\hline \multicolumn{3}{|l|}{ Insurance type } \\
\hline $\begin{array}{l}\text { Urban Employee Basic Medical } \\
\text { Insurance }\end{array}$ & 518 & 57.9 \\
\hline $\begin{array}{l}\text { Urban Resident-based Basic Medical } \\
\text { Insurance }\end{array}$ & 181 & 20.3 \\
\hline $\begin{array}{l}\text { New Rural Cooperative Medical } \\
\text { Scheme }\end{array}$ & 195 & 21.8 \\
\hline \multicolumn{3}{|l|}{ Education } \\
\hline$\leq$ Junior school & 675 & 75.5 \\
\hline Senior school & 141 & 15.8 \\
\hline$\geq$ College & 78 & 8.7 \\
\hline \multicolumn{3}{|l|}{ Place of death } \\
\hline Health institution & 558 & 62.4 \\
\hline Home & 336 & 37.6 \\
\hline \multicolumn{3}{|l|}{ Survival time from cancer diagnosis* } \\
\hline$<3$ months & 260 & 29.3 \\
\hline $3-6$ months & 231 & 26.0 \\
\hline $7-12$ months & 219 & 24.6 \\
\hline$>12$ months & 179 & 20.1 \\
\hline
\end{tabular}

\section{RESULTS}

\section{Characteristics of the patients and ICD-10 code}

As shown in table 1, 894 patients were included in this study. The median age of enrolled patients was 69 (range, 25-102) years, $35.2 \%$ of which were younger than 65 years, and $15.6 \%$ were older than 80 years. Two-thirds $(66.8 \%)$ of these patients were male, and $83 \%$ of the 894 patients were married. A total of $57.9 \%, 20.3 \%$ and $21.8 \%$ of the patients were enrolled in Urban Employee Basic Medical Insurance (UEBMI), Urban Resident-based Basic Medical Insurance (URBMI) and the New Rural Cooperative Medical Scheme (NRCMS), respectively. About $75.5 \%$ of the patients finished junior school or below, and $44.7 \%$ survived for at least 6 months. A total of $62.4 \%$ of the patients died in hospitals. As shown in table 2, the most common cancer types were lung cancer $(34.7 \%)$, liver cancer $(14.0 \%)$ and colorectal cancer $(9.5 \%)$.

\section{Healthcare utilisation and cost}

As shown in table 3 , the average numbers of outpatient and inpatient hospitalisation services were 4.86 and 2.23 times per capita, respectively. The ED and ICU visits were 1.44 and 0.06 times per capita, respectively. A total of $5.9 \%(53 / 894)$ of the patients were admitted once into the ICU, and $49.7 \%(444 / 894)$ visited the ED only once. The average expenditures per capita during the last 1 week, 1 month, 3 months and 6 months were US $\$ 2085$, US $\$ 6349$, US $\$ 13043$ and US $\$ 18$ 235, respectively. The population-level costs in the last 1 week, 1 month and 3 months were, on average, $11.4 \%, 34.8 \%$ and $71.5 \%$, respectively, of the last 6 months.

\section{Determinants of EOL healthcare cost}

As shown in table 4, all the results revealed proportionate changes in health expenditures among the different groups. In the four generalised linear models, gender, marital status and education levels of the patients showed statistically insignificant differences in the costs during the four different EOL periods. High EOL healthcare expenditure was associated with the age of first diagnosis, insurance type, place of death, survival after diagnosis and aggressive care services.

For age, we can see that patients aged between 65 and 80 years spent $66.8 \%$ and $34.7 \%$ more than the oldest groups $(\mathrm{OR}=1.322, \mathrm{p}=0.033,95 \% \mathrm{CI}=1.022$ to 1.710$)$ and younger patients $(\mathrm{OR}=1.347, \mathrm{p}=0.036,95 \%$ $\mathrm{CI}=1.02$ to 1.779 ) on the cost during the last 6 months and 3 months, respectively. Patients with UEBMI spent more than those with URBMI and the NRCMS in the last 6 months $(\mathrm{OR}=1.79, \mathrm{p}<0.001,95 \% \mathrm{CI}=1.313$ to 2.44; $\mathrm{OR}=1.480, \mathrm{p}=0.002,95 \% \mathrm{CI}=1.160$ to 1.887$), 3$ months $(\mathrm{OR}=2.172, \mathrm{p}<0.001,95 \% \mathrm{CI}=1.464$ to 3.222 ; $\mathrm{OR}=1.668$, $\mathrm{p}=0.002, \quad 95 \% \quad \mathrm{CI}=1.206$ to 2.305$)$ and 1 month $(\mathrm{OR}=2.132, \mathrm{p}<0.001,95 \% \mathrm{CI}=1.46$ to 3.113 ; $\mathrm{OR}=1.581$, $\mathrm{p}=0.004,95 \% \mathrm{CI}=1.161$ to 2.152$)$. Patients with the NRCMS spent between $98.2 \%(\mathrm{OR}=1.982, \mathrm{p}=0.005,95 \%$ $\mathrm{CI}=1.228$ to 3.2 ) and $153.2 \%$ ( $\mathrm{OR}=2.532, \mathrm{p}<0.001,95 \%$ $\mathrm{CI}=1.548$ to 4.139 ) higher than the URBMI group during the last week. Patients who died in the hospitals spent 1.488-fold ( $\mathrm{p}=0.002,95 \% \mathrm{CI}=1.187$ to 1.864 ), 2.323-fold $(\mathrm{p}<0.001,95 \% \mathrm{CI}=1.712$ to 3.151$), 3.481$-fold $(\mathrm{p}<0.001$, 95\% CI=2.585 to 4.688$)$ and 3.246-fold higher $(\mathrm{p}<0.001$, $95 \% \mathrm{CI}=2.427$ to 4.341$)$ than those who died at home during the four EOL periods.

For the survival time, the difference between the patients who survived for 7-12 months and those who survived for longer than 12 months was not statistically significant $(\mathrm{OR}=1.026, \mathrm{p}=0.787,95 \% \mathrm{CI}=0.854$ to 1.231$)$. The cost during the last 3 months for patients who survived longer than 12 months was $31.7 \%$ (OR=0.682, $\mathrm{p}=0.032,95 \%$ $\mathrm{CI}=0.482$ to 0.968$)$ less than that of the reference group (<3-6 months). Differences between the four groups were also observed on the cost during the last 1 week. The 
Table 2 The ICD-10 codes of first cancer type when diagnosed

\begin{tabular}{llrr} 
First cancer type & Codes & Patients $(\mathbf{n = 8 9 4 )}$ & \% \\
\hline Lung & C34.x & 310 & 34.7 \\
Stomach & C16.x & 60 & 6.7 \\
Colorectum & C18.x, C19.x and C20.x & 85 & 9.5 \\
Liver & C22.x & 125 & 14.0 \\
Pancreas & C25.xl & 39 & 4.4 \\
Biliary tract & C23.x and C24.x & 19 & 2.1 \\
Blood & C81.x-C86.x and C91.x-C95.x & 0 & 0 \\
Prostate & C61.x & 15 & 1.7 \\
Breast & C50.x & 28 & 3.1 \\
Others & C00.x-C15.x, C17.x, C21.x, C26.x, C30.x-C33.x, & 213 & 23.8 \\
& C37.x-C41.x, C43.x-C49.x, C51.x-C58.x, & \\
& C60.x, C62.x, C80.x, C88.x, C90.x, C96.x and C97.x & & \\
\end{tabular}

ICD-10, International Statistical Classification of Diseases and Related Health Problems, 10th Revision.

mean costs estimated during the last 1 week of the groups who survived for 3-6 months $(\mathrm{OR}=0.624, \mathrm{p}=0.023,95 \%$ $\mathrm{CI}=0.416$ to 0.937$), 7-12$ months $(\mathrm{OR}=0.54, \mathrm{p}=0.007$, $95 \% \mathrm{CI}=0.346$ to 0.845 ) and longer than 12 months ( $\mathrm{OR}=0.346, \mathrm{p}<0.001,95 \% \mathrm{CI}=0.199$ to 0.599$)$ were less than patients who survived less than 3 months. Moreover, patients with $7-12$ months $(\mathrm{OR}=0.554, \mathrm{p}=0.017,95 \%$ $\mathrm{CI}=0.341$ to 0.900 ) and longer survival spent less than patients surviving between 3 and 6 months $(\mathrm{OR}=1.602$, $\mathrm{p}=0.023,95 \% \mathrm{CI}=1.067$ to 2.405$)$. Patients with more than 12 months of survival also spent $(\mathrm{OR}=0.640, \mathrm{p}=0.048$, $95 \% \mathrm{CI}=0.411$ to 0.997 ) less than those who survived 7-12 months. For the inpatient hospitalisation and ICU services, once the inpatient hospitalisation and ICU services increased by one time, the cost with the four periods increased $30.5 \%(\mathrm{p}<0.001,95 \% \mathrm{CI}=1.25$ to 1.362$)$ and $83.5 \%(\mathrm{p}<0.001,95 \% \mathrm{CI}=1.292$ to 2.606$), 35.3 \%$ $(\mathrm{p}<0.001, \quad 95 \% \quad \mathrm{CI}=1.187 \quad$ to 1.864$)$ and $113.7 \%$ $(\mathrm{p}<0.001,95 \% \quad \mathrm{CI}=1.253$ to 1.461$), 35.7 \% \quad(\mathrm{p}<0.001$, $95 \% \quad \mathrm{CI}=1.248$ to 1.477$)$ and $202.5 \% \quad(\mathrm{p}<0.001$, $95 \% \mathrm{CI}=1.994$ to 5.152$)$, and $35.3 \% \quad(\mathrm{p}<0.001,95 \%$
$\mathrm{CI}=1.245 \quad$ to 1.471$) \quad$ and $222.9 \% \quad(\mathrm{p}<0.001, \quad 95 \%$ $\mathrm{CI}=2.07$ to 5.038 ), respectively.

\section{DISCUSSION}

Many studies have noted that aggressive treatment during the EOL of a patient can lead to higher costs. ${ }^{17}{ }^{18}$ In this study, patients with end-stage cancer had high rates of hospitalisation and an average admission of 2.23 times in the last 6 months of life. A total of $5.9 \%$ of the cancer patients had used ICU services during the EOL period. A comparative study in seven developed countries showed that $40.3 \%$ of patients were admitted to the ICU in the USA and approximately $18 \%$ of patients were admitted to the ICU in the six other countries. ${ }^{42}$ The mean cost is US $\$ 18234$ per capita, which is lower than those of developed countries, such as Canada (US\$21 840), Norway (US\$19 783), the USA (US\$18 500), ${ }^{42}$ South Korea, Japan and Taiwan (annual cost of US\$68773 in 2010). ${ }^{43}$ The cost increased dramatically as death approached, similar to the results that SEER-Medicare costs revealed. ${ }^{44} \mathrm{We}$

\begin{tabular}{lllll}
\hline \multicolumn{4}{l}{ Table 3} & Healthcare services utilisation and cost of the enrolled patients* \\
\hline Variable & Mean & Standard error & Median & Range \\
\hline Outpatient services & 4.86 & 7.67 & 2 & 59 \\
Inpatient hospitalisation services & 2.23 & 2.16 & 2 & 39 \\
Emergency department visit & 1.44 & 2.91 & 1 & 13 \\
Intensive care unit admission & 0.06 & 0.25 & 0 & 2 \\
Cost during the last 1 week & 2085 & 6829 & 1195 & 66437 \\
Cost during the last 1 month & 6349 & 18469 & 6640 & 195182 \\
Cost during the last 3 months & 13043 & 37434 & 13901 & 431158 \\
Cost during the last 6 months & 18234 & 34583 & 19276 & 723144 \\
\hline
\end{tabular}

${ }^{*}$ The international purchasing power parities using rate for Chinese Yuan to US\$ (¥2.03=US\$1) in health from International Comparison Program 2011. 


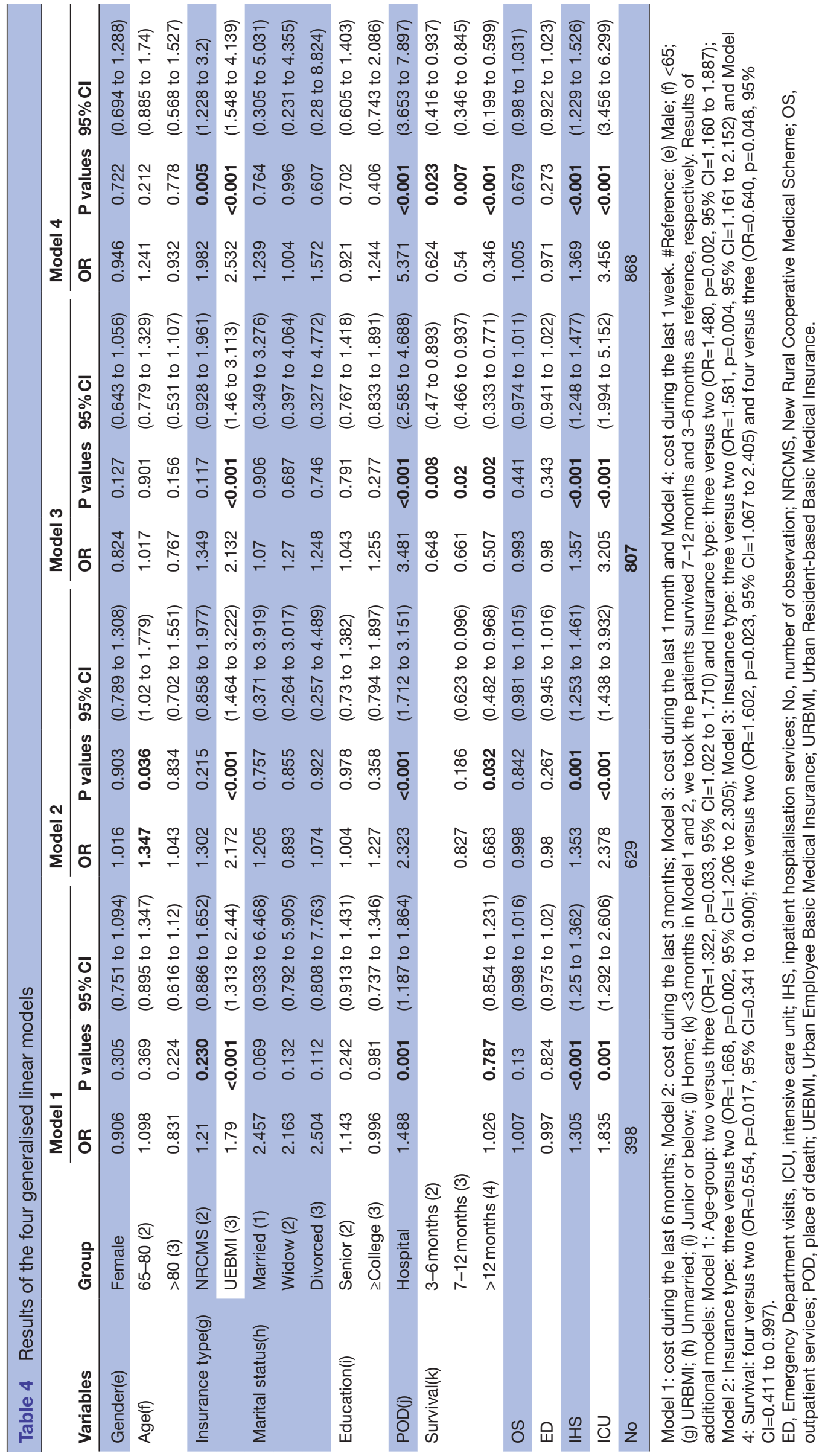


also found that cost increased rapidly in the last 1 month, indicating excessive treatment and ineffective medical expenses. Considering the current status of EOL healthcare utilisation and the expenditures trajectory, the risk factors of the high EOL cost must be investigated.

In this study, several determinants were identified that were associated with the higher EOL cost. First, high EOL healthcare expenditure was associated with young age due to high hospital care intensity. This result is consistent with those of previous studies. ${ }^{44-46}$ Many studies indicated that gender ${ }^{4647}$ and marital status ${ }^{48}$ were not facilitative determinants of the increased EOL healthcare cost. Second, striking disparities were also observed among the different medical insurances, which is consistent with the study of Zeng et al. ${ }^{49}$ Patients enrolled in the NRCMS spent more than those enrolled in URBMI during the last week. This phenomenon may be related to the traditional Chinese concept of death and suggests ineffective and irrational utilisation and low-value service provision. ${ }^{50}$ However, this finding is inconsistent with the conclusion that patients prefer to receive relatively passive care in Taiwan. ${ }^{43}$ Third, cost also depends on the place of death, and cost increased rapidly as death approached. The percentage $(62.42 \%)$ of patients who died in hospitals in China was higher than patients in the USA $(29.5 \%)$ and Canada $(52 \%) .{ }^{42}$ However, in the USA, $74 \%$ of non-hospice beneficiaries died in hospitals or skilled nursing facilities compared with the $14 \%$ who died receiving hospice care. ${ }^{51}$ Fourth, the effect of survival on EOL cost differed among patients with different survival periods suggesting that the patients with poor cancer prognosis in the present study may have high rates of aggressive care at the EOL period. Moreover, inpatient hospitalisation and ICU services were risk factors for high EOL cost. An ED visit in China is not a risk factor for the increase in cost, which may be due to the current operation process wherein patients are usually hospitalised once admitted during ED visits. ${ }^{52}$ One study by Obermeyer $e t$ $a \tilde{l}^{\tilde{3}}$ revealed that Medicare fee-for-service beneficiaries with poor-prognosis cancer, which were enrolled in the hospice care programme, used less hospitalisation, ICU admissions and invasive procedures with a lower total cost than the non-hospice group. Hence, there is great potential for the development of hospice care programmes in China.

The abovementioned results indicated that numerous health resources in China might be ineffectively used, similar to other countries. ${ }^{54}$ Patients receiving hospice care or early palliative care intervention could experience better management of pain and symptom ${ }^{55}$ and an improved likelihood of dying at home if that was preferred. ${ }^{12}{ }^{52}$ Given the potential benefits of hospice care and early palliative care intervention, the timely initiation of hospice or home care may reduce low-value cancer healthcare services in China. The overuse of aggressive care during the EOL period can be harmful from the perspective of the patients, including additional care-related financial strain, ${ }^{14}$ no reduction in the bereavement of their families. ${ }^{18}{ }^{56}$ Given the potential benefits of hospice care and early palliative care intervention, the healthcare need of patients should be satisfied. The timely initiation of hospice or home care may reduce the low-value cancer healthcare services in China.

\section{CONCLUSION}

According to real-world data, this study provides comprehensive evidence on healthcare utilisation and expenditure for cancer patients during the EOL period in China. This study revealed the potentially ineffective and irrational utilisation of medical resources and the urgency to improve hospice care systems in China. Overall, this study may aid in formulating specific measures to optimise the current cancer care delivery system, especially at the developing stages of the hospice care system. Future studies should focus on the evaluation of the current system on the provincial or national levels.

Acknowledgements We thank all the staff involved in the establishment of the Yichang Health Management Data Analysis Center, including experts from the Yichang Center for Disease Control and Prevention.

Contributors ZL, ZP, PZ, LZ and BL designed this study; ZL, ZP, CX and FL collected and analyzed the data; ZL drafted the manuscript; RH, SJ, BL and LZ modified the manuscript. All authors read and approved the final manuscript.

Funding This project was funded by the National Natural Science Foundation of China (71734003 and 71804053) and Humanities and Social Sciences project (HSS) of Ministry of Education of China(13YJC630070).

Competing interests None declared.

Patient consent for publication Not required.

Ethics approval This study was approved by the Ethics Committee of the Tongji Medical College, Huazhong University of Science and Technology.

Provenance and peer review Not commissioned; externally peer reviewed.

Data sharing statement All the research data is available upon reasonable request.

Open access This is an open access article distributed in accordance with the Creative Commons Attribution Non Commercial (CC BY-NC 4.0) license, which permits others to distribute, remix, adapt, build upon this work non-commercially, and license their derivative works on different terms, provided the original work is properly cited, appropriate credit is given, any changes made indicated, and the use is non-commercial. See: http://creativecommons.org/licenses/by-nc/4.0/.

\section{REFERENCES}

1. Torre LA, Bray F, Siegel RL, et al. Global cancer statistics, 2012. CA Cancer J Clin 2015;65:87-108.

2. Farmer P, Frenk J, Knaul FM, et al. Expansion of cancer care and control in countries of low and middle income: a call to action. Lancet 2010;376:1186-.

3. Jönsson B, Hofmarcher T, Lindgren P, et al. The cost and burden of cancer in the European Union 1995-2014. Eur J Cancer 2016;66:162-70.

4. Røe OD. The high cost of new cancer therapies-a challenge of inequality for all countries. JAMA Oncol 2017;3:1169-70.

5. Ramsey S. What do we want from our investment in cancer research? Health Aff 2005;24 Suppl 2:W5-R101-W5-R104.

6. Sullivan R, Peppercorn J, Sikora K, et al. Delivering affordable cancer care in high-income countries. Lancet Oncol 2011;12:933-80.

7. Bainbridge D, Seow H, Sussman J. Common components of efficacious in-home end-of-life care programs: a review of systematic reviews. J Am Geriatr Soc 2016;64:632-9.

8. Luckett T, Davidson PM, Lam L, et al. Do community specialist palliative care services that provide home nursing increase rates of home death for people with life-limiting illnesses? A systematic 
review and meta-analysis of comparative studies. J Pain Symptom Manage 2013;45:279-97.

9. Wennberg JE, Bronner K, Skinner JS, et al. Inpatient care intensity and patients' ratings of their hospital experiences. Health Aff 2009;28:103-12.

10. Chitnis XA, Georghiou T, Steventon A, et al. Effect of a home-based end-of-life nursing service on hospital use at the end of life and place of death: a study using administrative data and matched controls. BMJ Support Palliat Care 2013;3:422-30.

11. the Dartmouth Atlas of health care. Inpatient days per decedent during the last six months of life by gender and level of care intensity. $2015 \mathrm{http} / / /$ www.dartmouthatlas.org/data/topic/topic.aspx?cat=18.

12. Pizzo P, Walker D, Bomba P. Dying in America: Improving quality and honoring individual preferences near the end of life. Washington, DC: Insitute of Medicine, 2015

13. Divi V, Tao L, Whittemore A, et al. Geographic variation in Medicare treatment costs and outcomes for advanced head and neck cancer. Oral Oncol 2016;61:83-8.

14. Pivodic L, Van den Block L, Pardon K, et al. Burden on family carers and care-related financial strain at the end of life: a cross-national population-based study. Eur J Public Health 2014;24:819-26.

15. Earle CC, Landrum MB, Souza JM, et al. Aggressiveness of cancer care near the end of life: is it a quality-of-care issue? J Clin Oncol 2008;26:3860-6.

16. Langton JM, Blanch B, Drew AK, et al. Retrospective studies of end-of-life resource utilization and costs in cancer care using health administrative data: a systematic review. Palliat Med 2014;28:1167-96.

17. Barnato AE, McClellan MB, Kagay CR, et al. Trends in inpatient treatment intensity among Medicare beneficiaries at the end of life. Health Serv Res 2004:39:363-75.

18. Wright AA, Keating NL, Ayanian JZ, et al. Family perspectives on aggressive cancer care near the end of life. JAMA 2016;315:284

19. Li Z, Jiang S, He R, et al. Trajectories of hospitalization cost among patients of end-stage lung cancer: a retrospective study in China. Int $J$ Environ Res Public Health 2018;15:2877.

20. National Center for Health Statistics and Information. The fifth national health service survey and analysis report, 2013.

21. Chen W, Zheng R, Baade PD, et al. Cancer statistics in China, 2015. CA Cancer J Clin 2016;66:115-32.

22. Zeng $\mathrm{H}$, Chen $\mathrm{W}$, Zheng $\mathrm{R}$, et al. Changing cancer survival in China during 2003-15: a pooled analysis of 17 population-based cancer registries. Lancet Glob Health 2018;6:e555-e567.

23. World Bank Group, World Health Organization, Ministry of Finance, National Health and Family Planning Commission, Ministry of Human Resources and Social Security. Health China: deepening health reform in china building high-quality and value-based service quality. https:// openknowledge.worldbank.org/bitstream/handle/10986/ 24720/ HealthReformInChina.pdf (Accessed 29 Apr 2018)

24. Unit El. The 2015 quality of death index: ranking palliative care across the world. $2015 \mathrm{https} / / / \mathrm{www}$.eiuperspectives.economist. $\mathrm{com} / \mathrm{sites} /$ default/files/2015\%20EIU\%20Quality\%20of\%20Death\% 20Index\%200ct\%2029\%20FINAL.pdf.

25. Huang $\mathrm{H}-\mathrm{Y}$, Shi J-F, Guo L-W, et al. Expenditure and financial burden for common cancers in China: a hospital-based multicentre crosssectional study. The Lancet 2016;388:S10.

26. Narang AK, Nicholas LH. Out-of-pocket spending and financial burden among medicare beneficiaries with cancer. JAMA Oncol 2017;3:757

27. Yang T, Chu J, Zhou C, et al. Catastrophic health expenditure: a comparative analysis of empty-nest and non-empty-nest households with seniors in Shandong, China. BMJ Open 2016;6:e010992.

28. Wang Z, Li X, Chen M. Catastrophic health expenditures and its inequality in elderly households with chronic disease patients in China. Int J Equity Health 2015;14:8.

29. An H, Sun J, Zhao J. Research on the palliative care nursing for the patients with end-stage cancer. Practice and Research on Nursing 2008;5:65-6. [in Chinese].

30. Ethical reflection of the health resource allocation for the palliative care services - - an study on the medical cost of 215 patients with the end-stage cancer. Chinese Journal of Medical Ethics 1995;4:26-7. [in Chinese].

31. Shi JF, Shi CL, Yue XP, et al. [Economic burden of cancer in China during 1996-2014: a systematic review]. Zhonghua Zhong Liu Za Zhi 2016;38:929-41.
32. WHO. The International Statistical Classification of Diseases and Related Health Problems 10th Revision (ICD-10).

33. Tangka FK, Subramanian S, Sabatino SA, et al. End-of-life medical costs of medicaid cancer patients. Health Serv Res 2015;50:690-709.

34. Earle CC, Neville BA, Landrum MB, et al. Trends in the aggressiveness of cancer care near the end of life. $J$ Clin Oncol 2004;22:315-21.

35. Earle CC, Neville BA, Landrum MB, et al. Evaluating claims-based indicators of the intensity of end-of-life cancer care. Int J Qual Health Care 2005;17:505-9.

36. Setoguchi S, Earle CC, Glynn R, et al. Comparison of prospective and retrospective indicators of the quality of end-of-life cancer care. $J$ Clin Oncol 2008;26:5671-8.

37. Grunfeld E, Urquhart R, Mykhalovskiy E, et al. Toward populationbased indicators of quality end-of-life care. Cancer 2008;112:2301-8.

38. Grunfeld E, Lethbridge L, Dewar R, et al. Towards using administrative databases to measure population-based indicators of quality of end-of-life care: testing the methodology. Palliat Med 2006;20:769-77.

39. World Bank Group, ICP. International comparison program. 2011 http://siteresources.worldbank.org/ICPEXT/Resources/ICP_2011. html.

40. Barber J, Thompson S. Multiple regression of cost data: use of generalised linear models. J Health Serv Res Policy 2004;9:197-204.

41. Diehr P, Yanez D, Ash A, et al. Methods for analyzing health care utilization and costs. Annu Rev Public Health 1999;20:125-44.

42. Bekelman JE, Halpern SD, Blankart CR, et al. Comparison of site of death, health care utilization, and hospital expenditures for patients dying with cancer in 7 developed countries. JAMA 2016;315:272.

43. Hung YN, Liu TW, Wen FH, et al. Escalating health care expenditures in cancer decedents' last year of life: a decade of evidence from a retrospective population-based cohort study in Taiwan. Oncologist 2017;22:460-9.

44. Bremner KE, Krahn MD, Warren JL, et al. An international comparison of costs of end-of-life care for advanced lung cancer patients using health administrative data. Palliat Med 2015;29:918-28

45. Gielen B, Remacle A, Mertens R. Patterns of health care use and expenditure during the last 6 months of life in Belgium: differences between age categories in cancer and non-cancer patients. Health Policy 2010;97:53-61.

46. Langton JM, Reeve R, Srasuebkul P, et al. Health service use and costs in the last 6 months of life in elderly decedents with a history of cancer: a comprehensive analysis from a health payer perspective. Br J Cancer 2016;114:1293-302.

47. Yabroff KR, Lamont EB, Mariotto A, et al. Cost of care for elderly cancer patients in the United States. J Natl Cancer Inst 2008;100:630-41.

48. Cabrera-Alonso J, Long MJ, Bangalore V, et al. Marital status and health care expenditures among the elderly in a managed care organization. Health Care Manag 2003;22:249-55

49. Zeng $\mathrm{H}$, Zheng R, Guo $\mathrm{Y}$, et al. Cancer survival in China, 2003-2005: a population-based study. Int J Cancer 2015;136:1921-30.

50. Zuckerman RB, Stearns SC, Sheingold SH. Hospice use, hospitalization, and medicare spending at the end of life. J Gerontol B Psychol Sci Soc Sci 2016;71:569-80.

51. O Z, M M, A S, et al. Association between the Medicare hospice benefit and health care utilization and costs for patients with poorprognosis cancer. JAMA 2014;312:1888-96.

52. Hou XY, Chu K. Emergency department in hospitals, a window of the world: a preliminary comparison between Australia and China. World J Emerg Med 2010;1:180

53. Obermeyer Z, Makar M, Abujaber S, et al. Association between the Medicare hospice benefit and health care utilization and costs for patients with poor-prognosis cancer. JAMA 2014;312:1888-96.

54. Davies NJ, Batehup L. Towards a personalised approach to aftercare: a review of cancer follow-up in the UK. $J$ Cancer Surviv 2011;5:142-51.

55. Temel JS, Greer JA, Muzikansky A, et al. Early palliative care for patients with metastatic non-small-cell lung cancer. N Engl J Med 2010;363:733-42.

56. Carlson MD, Herrin J, Du Q, et al. Impact of hospice disenrollment on health care use and medicare expenditures for patients with cancer. J Clin Oncol 2010;28:4371-5. 